Research Article

\title{
Improved Reactivity of Fly Ash-Slag Geopolymer by the Addition of Silica Fume
}

\author{
N. K. Lee, G. H. An, K. T. Koh, and G. S. Ryu \\ Structural Engineering Research Division, Korea Institute of Civil Engineering and Building Technology, 283 Goyangdae-Ro, \\ Ilsanseo-Gu, Goyang-Si, Gyeonggi-Do 10223, Republic of Korea
}

Correspondence should be addressed to G. S. Ryu; ryu0505@kict.re.kr

Received 16 December 2015; Accepted 17 February 2016

Academic Editor: Belal F. Yousif

Copyright (c) 2016 N. K. Lee et al. This is an open access article distributed under the Creative Commons Attribution License, which permits unrestricted use, distribution, and reproduction in any medium, provided the original work is properly cited.

\begin{abstract}
This study investigates the improved reactivity of a geopolymer based on a combination of fly ash and blast furnace slag (BFS) by the addition of silica fume. The geopolymer was synthesized by activating a mixture of fly ash, BFS, and three different types of silica fume with alkali activator. X-ray diffraction (XRD) and inductively coupled plasma-optical emission spectroscopy (ICP-OES) were utilized to characterize the reaction. The silicate structure was also analyzed by nuclear magnetic resonance (NMR) spectroscopy. From these results, it was found that the replacement of fly ash with the silica fume led to a significant decrease in the $\mathrm{Q}^{4}(1 \mathrm{Al})$ and an increase in the $\mathrm{Q}^{4}(2 \mathrm{Al}), \mathrm{Q}^{4}(3 \mathrm{Al})$, and $\mathrm{Q}^{4}(4 \mathrm{Al})$. The $\mathrm{Si} / \mathrm{Al}$ ratio of the aluminosilicate gel was relatively constant, ranging from 2.0 to 2.6, while the $\mathrm{Si} / \mathrm{Al}$ ratio of the C-S-H gel increased with the addition of silica fume. Therefore, some of the $\mathrm{Al}$ dissolved from the slag contributed to the formation of aluminosilicate gel, and the remnant slag particles mostly participated in the formation of the C-(A)-S-H gel with a decrease in the $\mathrm{Q}^{2}(1 \mathrm{Al})$. The increase in the reactivity of slag caused by the addition of silica fume was attributed to the reaction of the $\mathrm{Al}$ in the slag with the silica fume.
\end{abstract}

\section{Introduction}

Geopolymers have much potential as construction materials due to their excellent mechanical properties. They can be cured at ambient temperatures and emit less $\mathrm{CO}_{2}$ compared to Portland cement. Field applications of geopolymer concrete are increasing continuously around the world. For instance, geopolymer concrete has been applied to pavement at airports and to precast floor panels in buildings in Australia [1]. The application of geopolymer concrete for practical use mandates the verification of their durability and mechanical properties. In fact, the durability of geopolymer concrete is closely associated with its feasibility in the construction field. Several attempts have been made to improve the mechanical properties and durability of geopolymer concrete. In particular, the addition of silica fume rich in silica to geopolymers reportedly improves their performance capabilities and leads to the formation of a more highly polymerized product with high acid resistance compared to geopolymer with only fly ash [2-4].

Silica fume is known to be highly pozzolanic, and it enhances the resistance of concrete against severe conditions
[5-8]. Due to its high fineness and high silica content (more than $90 \%$ ), silica fume is utilized in concrete in order to enhance the properties of concrete, such as the compressive strength, bond strength, and corrosion resistance. In addition, it is widely used to enhance the durability of concrete because it decreases the permeability of concrete as a microfiller $[9,10]$ and enables it to resist corrosion [9].

The effect of silica fume on geopolymers has been explored in previous studies. In particular, Okoye et al. [11] investigated the effects of different dosages of silica fume in fly ash-based geopolymer concrete which were activated with $\mathrm{NaOH}$ and sodium silicate and cured in an oven at $100^{\circ} \mathrm{C}$. The results showed that the addition of silica fume improved the compressive strength levels of the geopolymer concretes. Geopolymer concretes incorporating silica fume were found to be highly resistant against exposure to $2 \%$ $\mathrm{H}_{2} \mathrm{SO}_{4}, 5 \% \mathrm{Na}_{2} \mathrm{SO}_{4}$, and $5 \% \mathrm{NaCl}$ solutions [11]. Thokchom et al. [12] found that the addition of silica fume up to $5 \%$ to a geopolymer mortar significantly enhanced the mechanical performance of the geopolymer mortar when exposed to a magnesium sulphate solution. The proper content of silica 
TABLE 1: Chemical composition of the binder materials.

\begin{tabular}{lccccc}
\hline Oxide (wt.\%) & Fly ash & Blast furnace slag (BFS) & Silica fume 1 (SF1) & Silica fume 2 (SF2) & Zirconium silica fume \\
\hline $\mathrm{CaO}$ & 3.0 & 43.7 & 0.3 & 0.4 & 0.2 \\
$\mathrm{SiO}_{2}$ & 62.8 & 34.7 & 96.0 & 96.4 & 93.0 \\
$\mathrm{Al}_{2} \mathrm{O}_{3}$ & 21 & 12.2 & 0.5 & 0.7 & 0.2 \\
$\mathrm{Fe}_{2} \mathrm{O}_{3}$ & 7.4 & 0.5 & - & 0.2 & 0.2 \\
$\mathrm{SO}_{3}$ & 0.8 & 3.3 & 0.3 & 0.5 & - \\
$\mathrm{MgO}$ & 0.9 & 3.4 & 0.9 & 0.8 & 0.5 \\
$\mathrm{P}_{2} \mathrm{O}$ & 1.4 & 0.7 & 0.4 & 0.7 & 4.4 \\
$\mathrm{~K}_{2} \mathrm{O}$ & 0.9 & 0.5 & - & - & 0.02 \\
$\mathrm{TiO}_{2}$ & 1.2 & 0.5 & & - \\
\hline
\end{tabular}

fume in geopolymers was investigated in a study where the compressive strength of a metakaolin-based geopolymer incorporating silica fume increased with the formation of a well-refined microstructure and a compact matrix with up to $7 \%$ substitution, after which it decreased slightly beyond this amount [9]. The compressive strength of a fly ash-based geopolymer increased with an increase in the nanosilica content up to $2 \%$ due to the densification of the microstructures with a well-connected interlocking morphology [13].

In the mercury intrusion porosimetry (MIP) results of a geopolymer mortar, the pore volume was lower in samples with additional silica fume [10]. Fine silica fume particles filled the voids between the sand particles and contributed to the decrease in the porosity, thus enhancing their mechanical properties. The addition of silica fume as a partial substitution for fly ash to a fly ash-based self-compacting geopolymer concrete caused a loss (4.3\%) of the workability [14], whereas the compressive strength increased by $6.9 \%$ and the flexural strength by $11.5 \%$ [15].

The current knowledge on the effects of silica fume on geopolymers remains limited, as research has not provided a clear understanding of the microstructures and reaction characteristics. The effects of the degree of silica availability on the geopolymer reaction were investigated in a study, with the result showing that higher silica availability resulted in a greater contribution of alumina to a geopolymer gel [16]. This was attributed to differences in the gel nucleation characteristics between a geopolymer with and a geopolymer without initially dissolved silica in the activating solution [16]. Given that no or very little $\mathrm{Ca}(\mathrm{OH})_{2}$ is present in fly ashbased geopolymer systems compared to alkali-activated slag, the formation of C-S-H gel by the pozzolanic reaction of $\mathrm{Ca}(\mathrm{OH})_{2}$ and silica fume is difficult. Because geopolymers consisting of both fly ash and slag contain multiple gels (e.g., N-A-S-H, C-A-S-H) with different characteristics [17], the content, chemical compositions, and silicate structures of these gels can be changed with the addition of silica fume to the geopolymer. Thus, the role of silica fume on the characteristics of fly ash-based geopolymers needs further clarification to realize improved durability of geopolymers. In this context, research on the effects of silica fume on the microstructures and reaction characteristics of geopolymers may provide new insight into improving the durability of these materials.
This study investigates the improved reactivity of a geopolymer based on a combination of fly ash and blast furnace slag (BFS) by the addition of silica fume. Three different types of silica fume were used. The test variables include the replacement of slag or fly ash with silica fume as well as the replacement percentages ( $0 \%, 10 \%$, and 20\%). The compressive strength of geopolymers with different types and different amounts of silica fume were measured, and X-ray diffraction (XRD) and inductively coupled plasma-optical emission spectroscopy (ICP-OES) were used to characterize reaction mechanism. In addition, the silicate structure was analyzed by nuclear magnetic resonance (NMR) spectroscopy.

\section{Experimental Program}

2.1. Materials. Class F fly ash (containing more than $70 \%$ pozzolanic compounds $\left(\mathrm{SiO}_{2}, \mathrm{Al}_{2} \mathrm{O}_{3}\right.$, and $\left.\mathrm{Fe}_{2} \mathrm{O}_{3}\right)$ in accordance with ASTM C618), BFS, and two types of silica fume (SF1 and SF2 supplied by Chemicon Co. and Elkem Co., Korea, resp.) were used as binder materials. The chemical compositions of these materials are listed in Table 1.

A powder type of alkali activator was prepared. It showed a chemical composition of $\mathrm{SiO}_{2}$ (47.0\%) and $\mathrm{Na}_{2} \mathrm{O}$ (50.0\%), a bulk density of $1.2 \mathrm{~g} / \mathrm{cm}^{3}$, and a molar ratio of 0.93 (Ms $=\mathrm{SiO}_{2} / \mathrm{Na}_{2} \mathrm{O}$ ). Distilled water was also used to dissolve the alkali activator powder.

2.2. Mixture Proportions. The mixture proportions are provided in Table 2 and are labeled with specific codes. The labels "SF1-," "SF2-," and "Z" represent SF1, SF2, and zirconium silica fume, respectively, as listed in Table 1. The labels "HFA," " 10 ," and " 20 " represent fly ash with high fineness and the two different silica fume contents (\%). For all of the samples, the fly ash was replaced with silica fume; however, for the samples labeled SF1-10S, SF1-20S, SF2-10S, and SF2-20S (with the last letter in the label being " $S$ "), the slag was replaced with silica fume.

The method used to produce the fly ash-slag geopolymer incorporating silica fume proceeded as follows. The fly ash, slag, silica fume, and alkali activator were dry-mixed for two minutes to ensure homogeneity of the mixture. Once water was added to the mixture, it was mixed for an additional two 
TABLE 2: Mix proportion of fly ash-slag geopolymer paste.

\begin{tabular}{lcccc}
\hline Sample & Water/binder & AA $^{*}$ water & $\mathrm{SF} /(\mathrm{FA}+\mathrm{BFS}+\mathrm{SF})$ & $\mathrm{FA} / \mathrm{BFS}$ \\
\hline $\mathrm{C}$ & 0.38 & 0.20 & 0 & 1.0 \\
SF1-10 & 0.38 & 0.20 & 0.10 & 0.8 \\
SF1-20 & 0.38 & 0.20 & 0.20 & 0.6 \\
Z10 & 0.38 & 0.20 & 0.10 & 0.8 \\
HFA & 0.38 & 0.20 & 0 & 1.0 \\
SF1-10S & 0.38 & 0.20 & 0.10 & 1.25 \\
SF1-20S & 0.38 & 0.20 & 0.20 & 1.67 \\
Z10S & 0.38 & 0.20 & 0.10 & 1.25 \\
SF2-10 & 0.38 & 0.20 & 0.10 & 0.8 \\
SF2-20 & 0.38 & 0.20 & 0.20 & 0.6 \\
SF2-10S & 0.38 & 0.20 & 0.10 & 1.25 \\
SF2-20S & 0.38 & 0.20 & 0.20 & 1.67 \\
\hline
\end{tabular}

${ }^{*} \mathrm{AA}$ indicates the alkaline activator with $\mathrm{SiO}_{2} / \mathrm{Na}_{2} \mathrm{O}$ ratio of 0.97 .

minutes. The geopolymer samples prepared were immediately cast into $50 \mathrm{~mm}$ cubic molds. All of the samples were cured at $60^{\circ} \mathrm{C}$ and at a relative humidity of $50 \%$ in a room with constant temperature and humidity levels for 24 hours. The samples were then removed from their molds and stored in a conditioning room until the day of testing.

2.3. Experimental Details. Compressive strength testing was conducted using a universal testing machine in accordance with ASTM C39 at 28 days. The geopolymer samples incorporating the silica fume were prepared by mechanical grinding for the XRD, ICP-OES, and NMR analyses. The XRD data were recorded on a Rigaku D/MAX-2500 machine using $\mathrm{Cu}$ $\mathrm{K} \alpha$ radiation at a scanning rate of $1^{\circ} / \mathrm{min}$ from $2^{\circ}$ to $70^{\circ}$ in the $2 \theta$ mode.

ICP-OES was used to determine the amounts of watersoluble silicon, aluminum, calcium, and sodium in the powdered geopolymer samples. The powdered geopolymer samples were sonicated in distilled water for two hours, and the amounts of the water-soluble elements were then measured by means of ICP-OES. The reactivity of the alkali activator was then calculated using (1), as introduced in Section 3.2. The initial dissolution content of the raw silica fume was measured in a batch dissolution experiment in a $\mathrm{NaOH}$ solution with a $\mathrm{pH}$ of 12.6 , which corresponds to that of the alkaline solution (alkali activator + mix water) used in the present study. The experiment was carried out in $500 \mathrm{~mL}$ polypropylene bottles at a temperature of $20 \pm 1^{\circ} \mathrm{C}$. To avoid the precipitation of hydrates, the ratio of the solution to the powdered geopolymer sample by weight was 500 . Silicon and aluminium concentrations were measured by ICP-OES.

${ }^{29} \mathrm{Si}$ solid-state NMR experiments were done using a Bruker AVANCE III HD $400 \mathrm{MHz}$ NMR system (at the KBSI Seoul Western Center) for the purpose of characterizing the silicate structure of the geopolymer incorporating the silica fume. The ${ }^{29} \mathrm{Si}$ resonance frequency was $79.5 \mathrm{MHz}$ and the spinning rate was $12 \mathrm{kHz}$. The delay time was $20 \mathrm{~s}$.

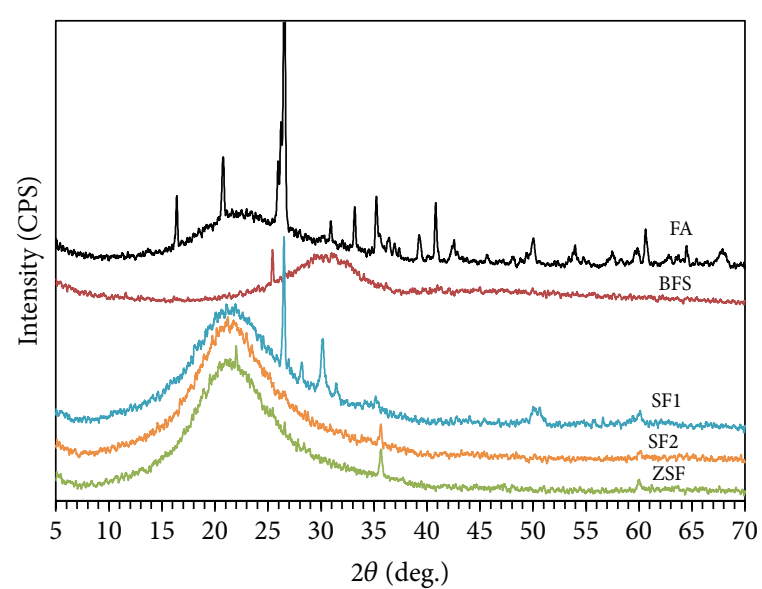

(a) Raw materials (FA: fly ash, BFS: blast furnace slag, SF1 and SF2: silica fume, ZSF: zirconium silica fume)

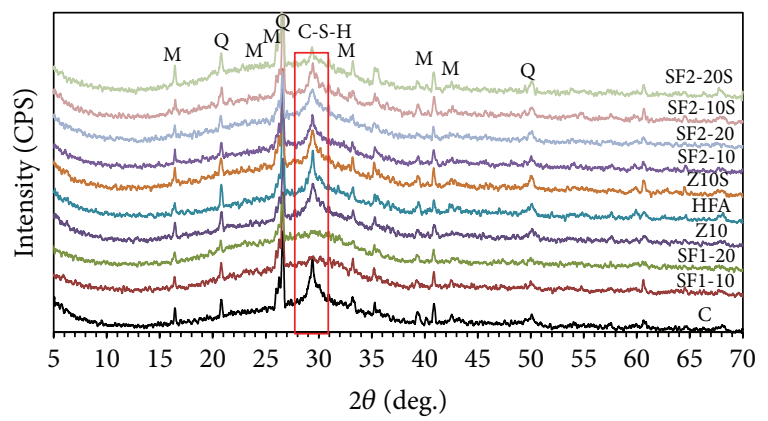

M: mullite

Q: quartz

C: C-S-H

(b) Fly ash-slag geopolymer incorporating various types and contents of silica fume

FIGURE 1: XRD patterns of raw materials and geopolymer incorporating silica fume.

\section{Results and Discussion}

3.1. Phase Identification Using X-Ray Powder Diffraction (XRD). Figure $1(\mathrm{a})$ shows the XRD patterns of the raw materials. Peaks corresponding to mullite and quartz were clearly observed in the raw fly ash, and a diffuse band at $25-35^{\circ}$ appeared due to the glassy components in the raw slag. A diffuse band at $15-30^{\circ}$ was observed in the raw silica fume, and there were only minor differences between SF1 and SF2 materials; however, a number of crystalline peaks were observed in zirconium silica fume.

Figure 1(b) shows the XRD patterns of the geopolymer samples. The presence of mullite and quartz, crystalline phases of fly ash, were commonly observed in all of the samples. It is important to note that peaks at $29-30^{\circ}$ were detected in all of the samples except for SF1-10 and SF1-20; they are very closely associated with C-S-H or $\mathrm{CaCO}_{3}[19,20]$. As both the fly ash and slag were mixed as a binder in the present study, aluminosilicate gel and C-S-H gel coexist in the geopolymer due to complex reaction mechanism [2123 . Because the geopolymer samples were overlapped with 
TABLE 3: Reactivity calculated from insoluble Si or Na element content of powder sodium silicate in distilled water (\%).

\begin{tabular}{lcccc}
\hline Sample ID & $\mathrm{Na}$ & $\mathrm{Si}$ & $\mathrm{Ca}^{*}$ & $\mathrm{Al}^{*}$ \\
\hline C & 45.1 & 95.7 & 87.6 & 96.4 \\
SF1-10 & 40.5 & 89.1 & 95.2 & 100 \\
SF1-20 & 48.7 & 90.1 & 98.2 & 100 \\
Z10 & 56.9 & 94.9 & 90.1 & 97.6 \\
HFA & 52.2 & 95.5 & 88.6 & 96.1 \\
Z10S & 60.1 & 92.4 & 87.4 & 96.8 \\
SF2-10 & 65.5 & 94.7 & 91.2 & 97.7 \\
SF2-20 & 65.8 & 90.8 & 94.6 & 100 \\
SF2-10S & 65.2 & 92.2 & 88.7 & 97.1 \\
SF2-20S & 64.4 & 90.9 & 97.0 & 100 \\
\hline
\end{tabular}

* Insoluble $\mathrm{Al}$ and $\mathrm{Ca}$ contents (\%) mean the percentage of the insoluble contents into the distilled water to the total $\mathrm{Al}$ and $\mathrm{Ca}$ contents in the geopolymer sample, respectively.

polypropylene film to prevent carbonation of the samples, the peaks are highly likely to be due to the presence of C-S-H gels in the geopolymer rather than $\mathrm{CaCO}_{3}$.

There was a likely correlation between the peak at 29$30^{\circ}$ and the compressive strength. In particular, this peak was not observed in SF1-10 and SF1-20, which showed the very low compressive strength of 3.2 and $3.4 \mathrm{MPa}$, respectively, as shown in Figure 6 . The peak intensity at $29-30^{\circ}$ in SF2-20 was lower than that in the samples showing the peak at 29$30^{\circ}$, and the compressive strength $(23.4 \mathrm{MPa})$ of SF2-20 was also lower than those of the samples. These results indicate that the presence of $\mathrm{C}-\mathrm{S}-\mathrm{H}$ was significant to achieve high compressive strength in the fly ash-slag based geopolymer.

\subsection{Reactivity of Alkali Activator in the Fly Ash-Slag Geopoly-} mer Incorporating Silica Fume. The reactivity of the alkali activator was determined by means of ICP-OES. Unreacted alkali activator can be dissolved in distilled water, while reacted alkali activator is difficult to dissolve in the distilled water owing to its chemical bonds with the reaction product [24]. It is assumed here that the reacted $\mathrm{Si}$ and $\mathrm{Na}$ of the alkali activator did not dissolve in the distilled water. However, the measured Si content dissolved in the distilled water cannot be regarded as only stemming from the unreacted Si of the alkali activator, as the alkali activator as well as raw fly ash and slag contain elemental Si. Hence, the measured Na content, which does not exist in raw fly ash and slag, can be regarded as the unreacted $\mathrm{Na}$ of alkali activator. The reacted $\mathrm{Na}$ content of the alkali activator was calculated by measuring the amount of dissolved $\mathrm{Na}$, and the reactivity of $\mathrm{Na}$ in the alkali activator was calculated as follows [24]:

$$
R_{\mathrm{Na}}=\left(1-\frac{E_{w}}{E_{o}}\right) \times 100(\%) .
$$

Here, $E_{w}$ denotes the $\mathrm{Na}$ content of the geopolymer dissolved in distilled water and $E_{o}$ is the total Si or Na content of the alkali activator.

Table 3 presents the reactivity as calculated from the insoluble $\mathrm{Si}$ or $\mathrm{Na}$ element content of alkali activator in

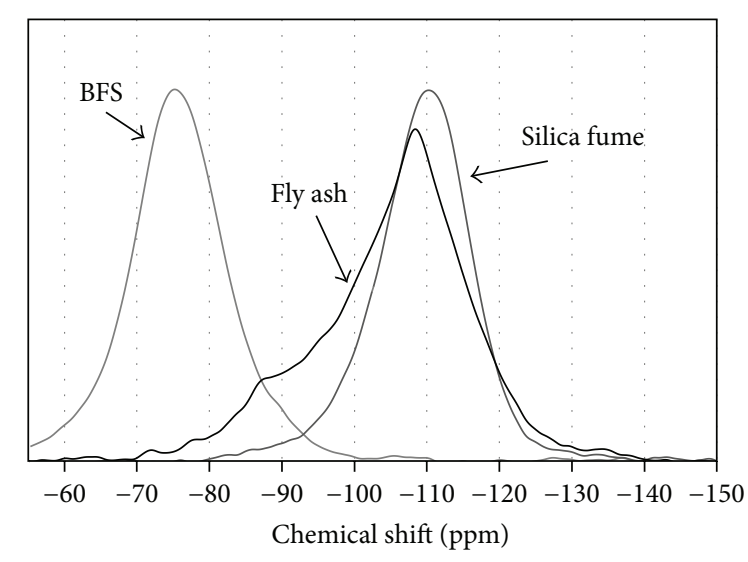

Figure $2:{ }^{29} \mathrm{Si}$ NMR spectra of raw materials.

distilled water (\%). The reactivity levels of the $\mathrm{Si}, \mathrm{Ca}$, and $\mathrm{Al}$ elements were all in the range of 90-100\%, indicating that most of the $\mathrm{Si}, \mathrm{Ca}$, and $\mathrm{Al}$ contributed to the geopolymer reaction. However, for the Si element, an additional experiment is required to calculate the insoluble content of Si in the alkali activator, as the alkali activator as well as raw fly ash and slag contain elemental $\mathrm{Si}$, as noted above. Because elemental $\mathrm{Na}$ exists in very low amounts in slag or fly ash, while existing at high rates in the alkali activator, the reactivity of alkali activator was determined by applying the measured insoluble $\mathrm{Na}$ content to (1). It was noted that the reactivity of $\mathrm{Na}$ ranged from $40 \%$ to $65 \%$, indicative of the ratio of $\mathrm{Na}$ content not dissolved in distilled water to the total $\mathrm{Na}$ content of the alkali activator. The reactivity of alkali activator decreased with the addition of $10 \%$ of SF1, while it increased with the addition of SF1 at a rate of $20 \%$ as compared to $\mathrm{C}$ without silica fume. The reactivity of alkali activator increased with the addition of SF2 regardless of the added SF2 content. The reactivity of alkali activator was much higher in the geopolymer incorporating SF2 rather than that incorporating SF1. The use of different types of silica fume affected the reactivity of alkali activator, thus affecting the compressive strength of the geopolymer.

\subsection{Silicate Structure as Measured by NMR Spectroscopy.} Figure 2 shows ${ }^{29} \mathrm{Si}$ NMR spectra of the raw materials. For the raw slag material, the peak at the maximum intensity level was $-75.7 \mathrm{ppm}$, while for the SF1, SF2, and ZSF materials, these values were $-109.8,-109.78$, and $-109.64 \mathrm{ppm}$, respectively. As shown in Figure 3(a), the spectrum of fly ash was deconvoluted into peaks corresponding to $\mathrm{Q}^{4}(n \mathrm{Al})$ sites using origin software. This information was used to analyze silicate structure of the geopolymer with the deconvoluted peaks of the ${ }^{29} \mathrm{Si}$ NMR spectra. The ${ }^{29} \mathrm{Si}$ NMR spectra, deconvoluted peaks, and total sum of the deconvoluted peaks of the geopolymer are shown in Figure 3.

The silicate structures of the geopolymers were analyzed, as shown in Table 4. The relative area (\%) values were calculated from the ${ }^{29} \mathrm{Si}$ NMR spectra and from the deconvolution results using origin software. The reactivity of the raw material and the reaction product content in the 


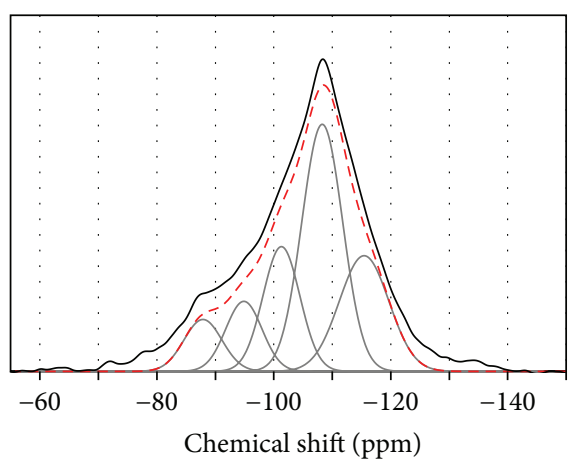

- Spectrum

(a) Raw fly ash

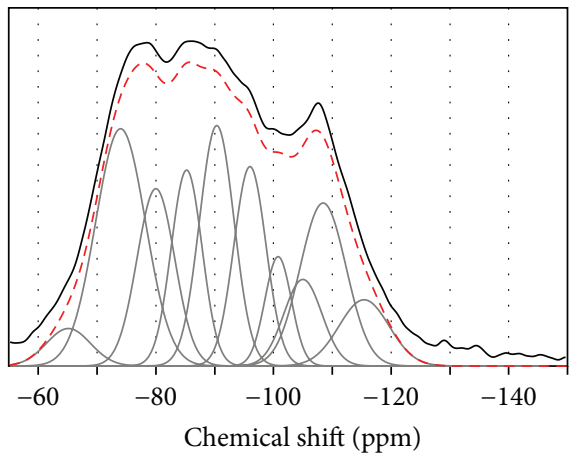

— Spectrum

- - Fit

(c) SF1-10

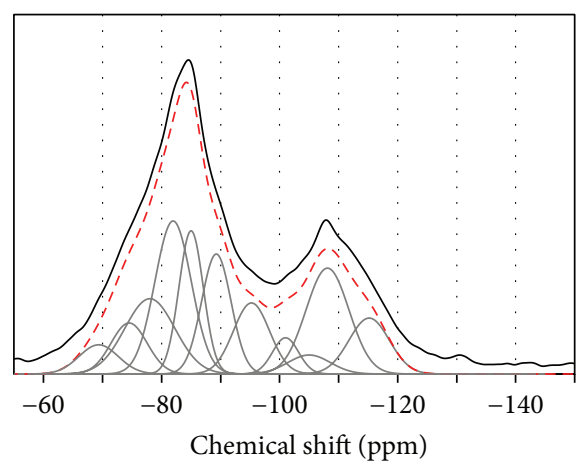

— Spectrum

(e) Z10

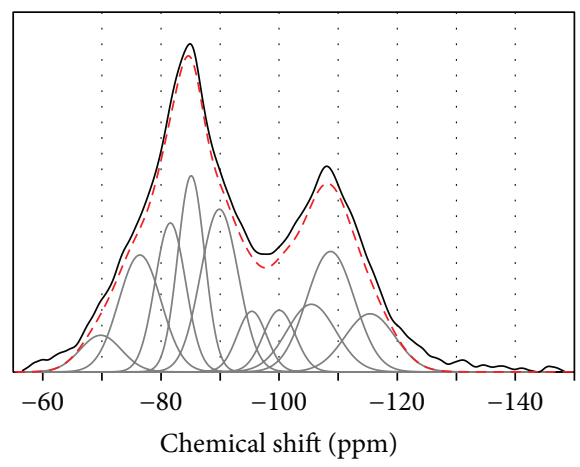

- Spectrum

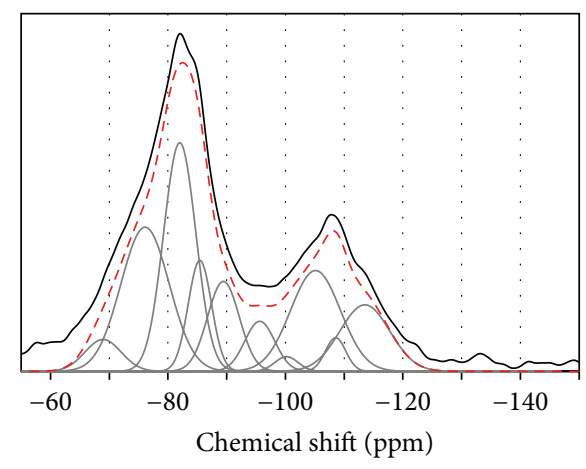

_ Spectrum

(b) Sample C

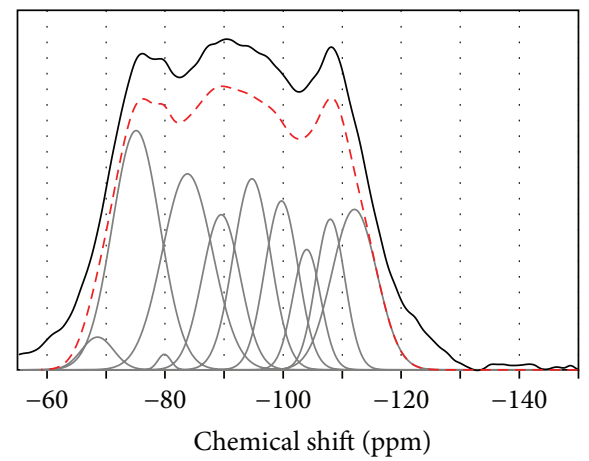

— Spectrum

-. - Fit

(d) SF1-20

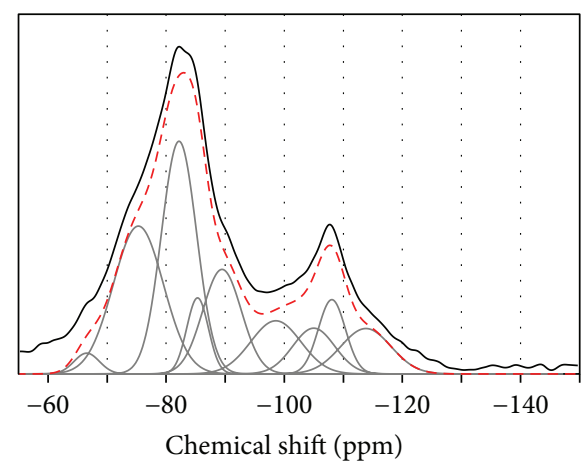

- Spectrum

- - Fit

(f) HFA

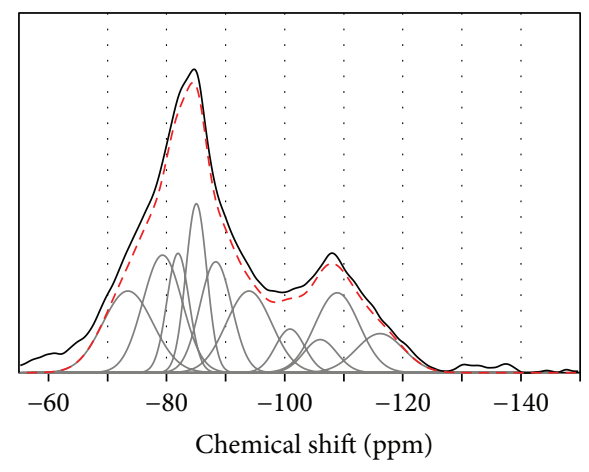

- Spectrum

-- - Fit

(h) SF2-10

(g) Z10S

Figure 3: Continued. 


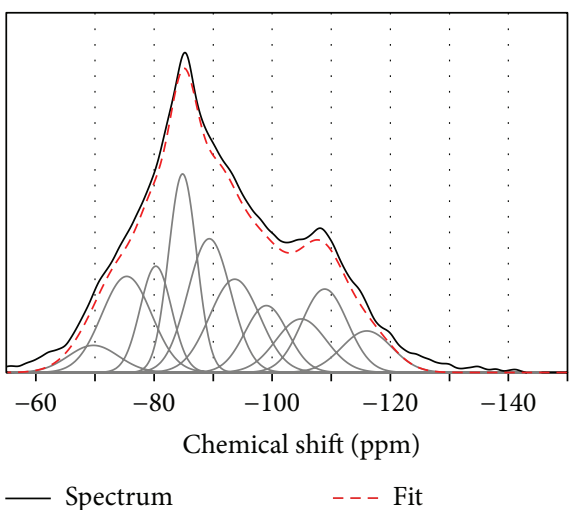

(i) SF2-20

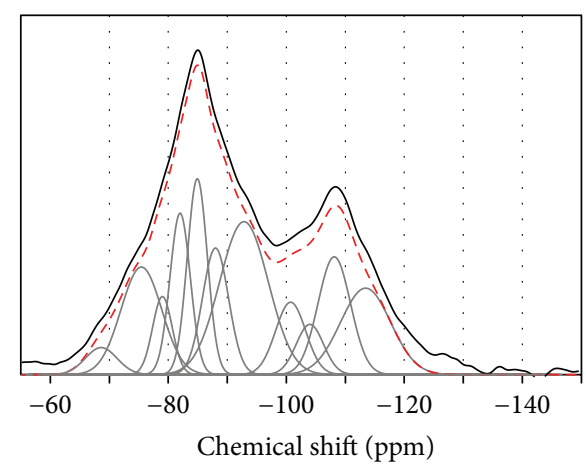

- Spectrum

(j) SF2-10S

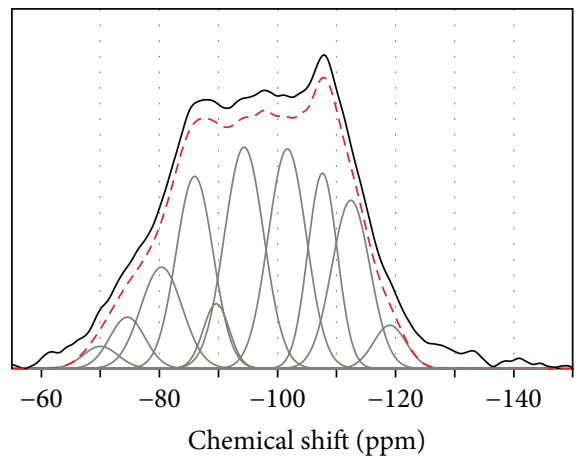

- Spectrum - - - Fit

(k) SF2-20S

FIGURE $3:{ }^{29}$ Si NMR spectra and deconvolution of fly ash-slag geopolymers.

TABLE 4: Area obtained from deconvolution results and peak analysis of ${ }^{29}$ Si NMR spectroscopy (\%).

\begin{tabular}{|c|c|c|c|c|c|c|c|c|c|}
\hline Sample & $\begin{array}{l}\text { Unreacted } \\
\text { slag }\end{array}$ & & C-S-H & & & & Aluminos & & \\
\hline Signal (ppm) & $-75^{\mathrm{a}}$ & $\begin{array}{c}\mathrm{Q}^{1} \\
-79\end{array}$ & $\begin{array}{c}\mathrm{Q}^{2}(1 \mathrm{Al}) \\
-81\end{array}$ & $\begin{array}{c}\mathrm{Q}^{2} \\
-85 \\
\end{array}$ & $\begin{array}{c}\mathrm{Q}^{4}(4 \mathrm{Al}) \\
-89\end{array}$ & $\begin{array}{c}\mathrm{Q}^{4}(3 \mathrm{Al}) \\
-95\end{array}$ & $\begin{array}{c}\mathrm{Q}^{4}(2 \mathrm{Al}) \\
-99\end{array}$ & $\begin{array}{c}\mathrm{Q}^{4}(1 \mathrm{Al}) \\
-104\end{array}$ & $\begin{array}{c}\mathrm{Q}^{4}(0 \mathrm{Al}) \\
-109^{\mathrm{b}}\end{array}$ \\
\hline Slag & 100 & - & - & - & - & - & - & - & - \\
\hline Fly $a h^{c}$ & - & - & - & - & - & 11.4 & 21.5 & - & 61.3 \\
\hline SF1 & - & - & - & - & - & - & - & - & 100 \\
\hline SF2 & - & - & - & - & - & - & - & - & 100 \\
\hline ZSF & - & - & - & - & - & - & - & - & 100 \\
\hline $\mathrm{C}$ & 22.4 & - & 20.4 & 7.2 & 10.4 & 5.4 & 1.2 & 18.3 & 14.6 \\
\hline SF1-10 & 27.2 & 11.5 & - & 11.3 & 12.6 & 9.7 & 5.5 & 7.6 & 14.6 \\
\hline SF1-20 & 27.5 & 0.5 & - & 22.0 & 8.6 & 10.5 & 8.3 & 5.4 & 17.2 \\
\hline $\mathrm{Z} 10$ & 0.92 & 12.0 & 17.6 & 11.2 & 11.6 & 8.6 & 3.5 & 3.3 & 23.0 \\
\hline HFA & 22.3 & - & 22.7 & 5.0 & 15.6 & - & 10.8 & 6.7 & 16.9 \\
\hline Z10S & 15.9 & - & 11.2 & 12.9 & 16.8 & 4.9 & 5.4 & 9.1 & 23.9 \\
\hline SF2-10 & 13.8 & 15.5 & 8.9 & 11.9 & 11.8 & 12.4 & 4.3 & 3.7 & 17.9 \\
\hline SF2-20 & 20.4 & - & 11.1 & 18.5 & 13.1 & 10.7 & 6.5 & 6.2 & 13.5 \\
\hline SF2-10S & 15.0 & 4.4 & 9.4 & 11.2 & 8.9 & 19.8 & 5.9 & 3.6 & 21.9 \\
\hline SF2-20S & 5.6 & - & 9.1 & 15.3 & 3.6 & 18.6 & 17.9 & 0.2 & 29.0 \\
\hline
\end{tabular}

${ }^{a}$ The peaks at $-77,-75$, and $-69 \mathrm{ppm}$ are attributed to the presence of raw slag in the geopolymer sample.

${ }^{\mathrm{b}}$ These are the peaks above $-109 \mathrm{ppm}$. Most of the peaks appearing above $-108 \mathrm{ppm}$ were assigned to different crystalline phases of silica $\left(\mathrm{Q}^{4}(0 \mathrm{Al})\right.$ signals $)$ [18].

${ }^{c}$ Fly ash has the signals related to $\mathrm{Q}^{4}(n \mathrm{Al})$ as well as the signal (87 $\left.\mathrm{ppm}\right)$ related to mullite (5.8\%). 


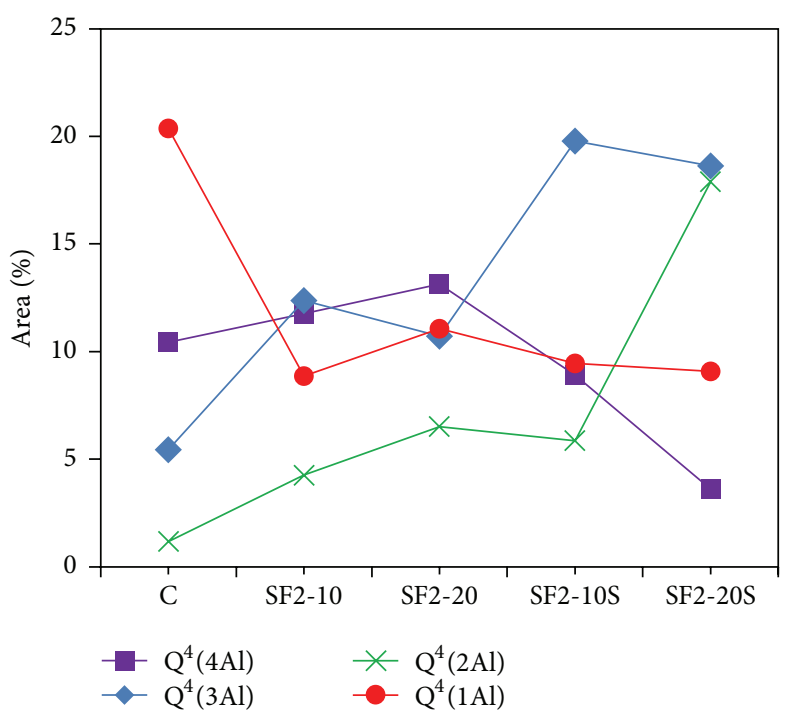

(a) $\mathrm{Q}^{4}(n \mathrm{Al})$ of aluminosilicate gel

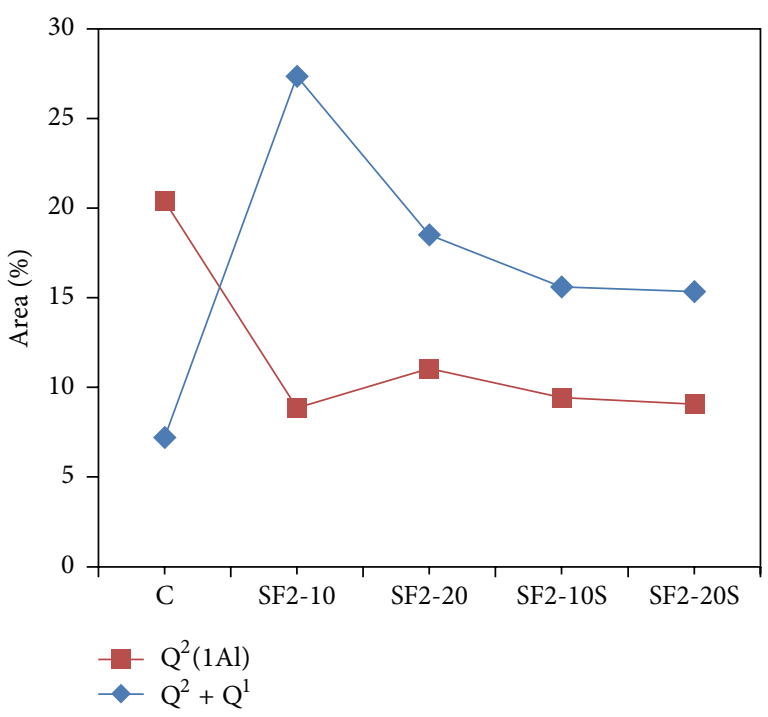

(b) $\mathrm{Q}^{1}, \mathrm{Q}^{2}$, and $\mathrm{Q}^{2}(1 \mathrm{Al})$ of C-S-H gel

FIGURE 4: Area (\%) of $\mathrm{Q}^{n}$ components of reaction products derived from Si NMR spectra.

geopolymer can be calculated using the relative area of the deconvoluted peaks corresponding to the $\mathrm{Q}^{4}(n \mathrm{Al})$ sites [25].

Figure 4 presents the area (\%) of the $\mathrm{Q}^{n}$ components of the reaction products as derived from the Si NMR spectra. In Figure 4(a), the replacement of fly ash with the silica fume at rates of $10 \%$ and $20 \%$ resulted in a decrease in the $\mathrm{Q}^{4}(1 \mathrm{Al})$ from 0.183 to 0.037 and 0.012 , respectively, whereas the $\mathrm{Q}^{4}(2 \mathrm{Al}), \mathrm{Q}^{4}(3 \mathrm{Al})$, and $\mathrm{Q}^{4}(4 \mathrm{Al})$ increased slightly. This tendency was also noted in the samples for which the slag was replaced by silica fume. The replacement of slag with silica fume at rates of $10 \%$ and $20 \%$ resulted in a decrease in the $\mathrm{Q}^{4}(1 \mathrm{Al})$ from 0.183 to 0.036 and 0.002 , respectively, while the $\mathrm{Q}^{4}(2 \mathrm{Al}), \mathrm{Q}^{4}(3 \mathrm{Al})$, and $\mathrm{Q}^{4}(4 \mathrm{Al})$ increased slightly compared to that of C. In only SF2-20S, the $\mathrm{Q}^{4}(4 \mathrm{Al})$ decreased compared to that of C.

These results clearly show the influence of silica fume on the silicate structure of geopolymers. If fly ash is replaced with silica fume in a geopolymer based on fly ash and slag, the $\mathrm{Si}$ content of the geopolymer increases while the $\mathrm{Al}$ content decreases. In Figure 5, the Si/Al ratio of aluminosilicate gel is strictly constant regardless of the incorporation of silica fume. In this regard, the decreased $\mathrm{Al}$ content resulting from the substitution of silica fume for fly ash is insufficient for the formation of aluminosilicate gel with the $\mathrm{Si} / \mathrm{Al}$ ratio of 2.0-2.6 in the geopolymer. Thus, additional Al should be supplied to the geopolymer. The additional Al necessary for the formation of aluminosilicate gel was supplied by the dissolution of the slag in the alkaline environment. In other words, the $\mathrm{Al}$ dissolved from the slag contributed to the formation of the aluminosilicate gel. Therefore, the incorporation of silica fume into the fly ash-slag geopolymer resulted in a decrease in the $\mathrm{Q}^{4}(1 \mathrm{Al})$ and increases in the $\mathrm{Q}^{4}(2 \mathrm{Al})$ and $\mathrm{Q}^{4}(3 \mathrm{Al}), \mathrm{Q}^{4}(4 \mathrm{Al})$, as shown in Figure $4(\mathrm{a})$. On the other hand, the slag particles mostly participated in the formation of the C-S-H gel, resulting in a decrease of the

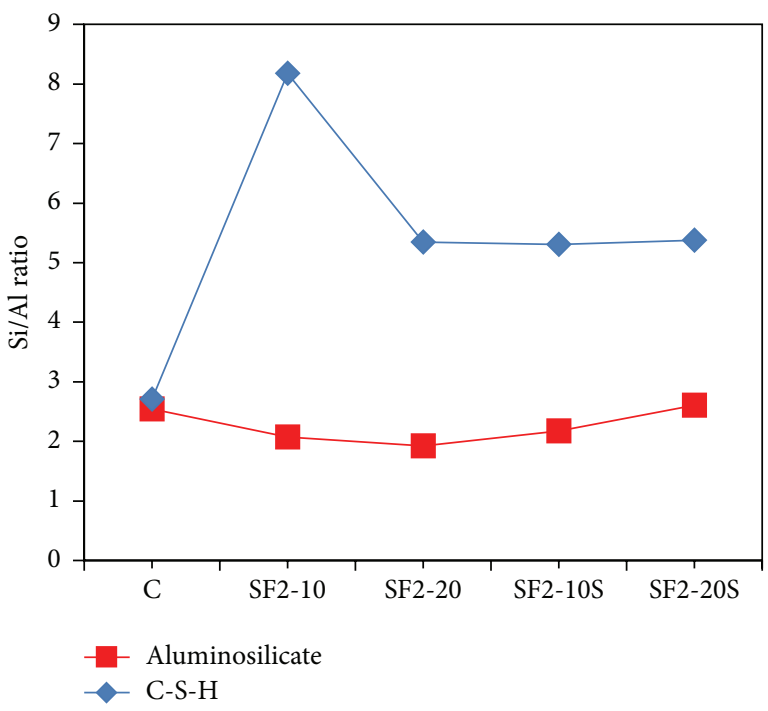

FIGURE 5: Si/Al ratio of reaction products calculated by applying $\mathrm{Si}$ MAS NMR spectra results to Engelhard's equation [18].

$\mathrm{Q}^{2}(1 \mathrm{Al})$ and an increase in the $\mathrm{Q}^{2}+\mathrm{Q}^{1}$ sites, as shown in Figure 4(b), due to the contribution of $\mathrm{Al}$ in the slag to the formation of the aluminosilicate gel.

This phenomenon is also observed in samples where the replacement rates of slag with silica fume were $10 \%$ and $20 \%$ by weight of the total binder. However, unlike the $\mathrm{Q}^{4}(4 \mathrm{Al})$ in SF2-10 and SF2-20, those in SF2-10S and SF2-20S were reduced significantly from 0.209 to 0.149 to 0.052 , respectively. The slag content in the geopolymer was decreased by the substitution of silica fume for slag. The reduced slag contents (30\% and $40 \%$ of the total binder) make it difficult to supply sufficient $\mathrm{Al}$ to form the aluminosilicate gel, which 
TABLE 5: Reactivity of raw material calculated by using NMR deconvolution peaks.

\begin{tabular}{lccc}
\hline Sample ID & Fly ash + silica fume & Slag & Total \\
\hline C $^{*}$ & 57.5 & 55.2 & 56.3 \\
SF1-10 & 48.4 & 45.6 & 46.8 \\
SF1-20 & 37.5 & 44.9 & 42.2 \\
Z10 & 35.6 & 81.5 & 61.1 \\
HFA $^{*}$ & 44.8 & 55.3 & 50.0 \\
Z10S & 43.2 & 60.2 & 50.8 \\
SF2-10 & 44.2 & 72.4 & 59.9 \\
SF2-20 & 48.6 & 59.1 & 55.2 \\
SF2-10S & 27.2 & 82.0 & 51.5 \\
SF2-20S & 24.8 & 81.4 & 46.0 \\
\hline
\end{tabular}

${ }^{*} \mathrm{C}$ and HFA indicate the reactivity of only fly ash.

disturbed the formation of $\mathrm{Q}^{4}(4 \mathrm{Al})$ in the aluminosilicate gel while also increasing the $\mathrm{Q}^{4}(2 \mathrm{Al})$ and $\mathrm{Q}^{4}(3 \mathrm{Al})$. The $\mathrm{Q}^{4}(2 \mathrm{Al})$ and $\mathrm{Q}^{4}(3 \mathrm{Al})$ increased with a decrease in the $\mathrm{Q}^{4}(4 \mathrm{Al})$ in order to maintain a constant $\mathrm{Si} / \mathrm{Al}$ ratio of the aluminosilicate gel ranging from 2.0 to 2.6. These results demonstrate that the addition of silica fume in the fly ash-slag geopolymer changed the silicate structure of C-S-H and the aluminosilicate gel, which may affect the durability of geopolymer concrete.

Table 5 presents the reactivity of the raw material and the total reactivity of the fly ash-slag geopolymer. Given that the peak position of silica fume was close to that of fly ash, it was difficult to analyze these two peaks separately. Accordingly, the reactivity of a binder containing fly ash and silica fume was calculated. As the amount of silica fume substituted for fly ash increased, the reactivity of the fly ash decreased and the reactivity of the slag decreased simultaneously with the addition of SF1 to the geopolymer, whereas it increased with the addition of SF2. The SF1-10 and SF1-20 samples showed relatively low reactivity values of $48.4 \%$ and $37.5 \%$, respectively, which may affect the compressive strength of a geopolymer. In HFA with fine fly ash, the reactivity of the fly ash was lower than that of $\mathrm{C}$, while that of the slag was nearly constant.

The addition of silica fume resulted in a decrease in the reactivity of the fly ash and in an increase in that of the slag. This tendency was more clearly shown when silica fume was substituted for slag rather than fly ash. Fly ash, consisting of amorphous and crystalline phases, generally has lower reactivity than silica fume which consists mostly of amorphous phases. Thus, it appears that the alkali activator reacted more favorably with the silica fume rather than with the fly ash. This is supported by the fact that addition of the silica fume resulted in an increase in the reactivity of $\mathrm{Na}$ in the alkali activator, as listed in Table 3 . The silica fume reacted strongly with the alkali activator, whereas the reactivity of fly ash with the alkali activator decreased. In addition, the increase in the reactivity of slag upon the addition of silica fume was attributed to the reaction of $\mathrm{Al}$ in the slag with the silica fume, as discussed with the $\mathrm{Si} / \mathrm{Al}$ ratios of the reaction products in Figure 5.

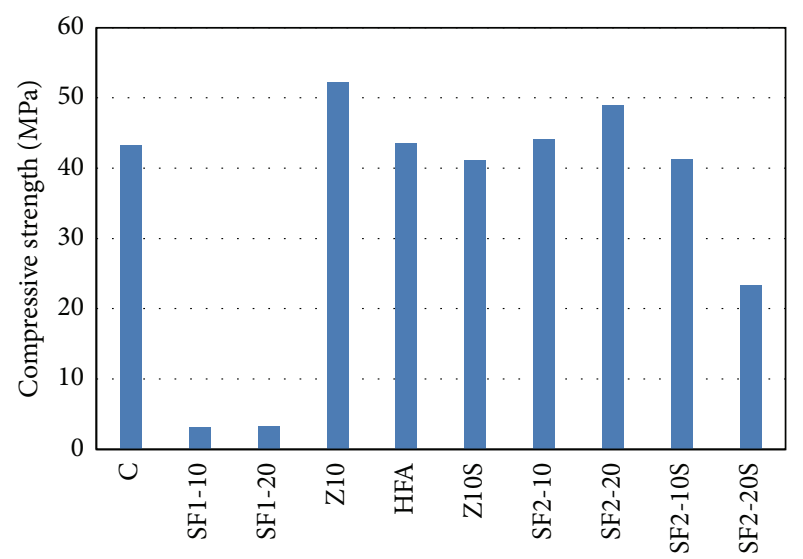

FIGURE 6: Compressive strength results of fly ash-slag geopolymers.

Figure 5 shows the $\mathrm{Si} / \mathrm{Al}$ ratios of the aluminosilicate and the $\mathrm{C}-\mathrm{S}-\mathrm{H}$ present in the geopolymer. The $\mathrm{Si} / \mathrm{Al}$ ratio of each reaction product was determined by applying Engelhardt's equation [18]. It should be noted that the $\mathrm{Si} / \mathrm{Al}$ ratio of aluminosilicate was relatively constant, at 2.0-2.6, while that of C-S-H changed remarkably depending on the amount of silica fume added. The Si/Al ratio of raw fly ash is 2.99 and that of raw slag is 2.81, as listed in Table 1. If silica fume containing alumina content of less than $1.0 \%$ is added, an additional supply of $\mathrm{Al}$ is required to form aluminosilicate gel with a $\mathrm{Si} / \mathrm{Al}$ ratio of 2.0-2.6. The additional $\mathrm{Al}$ can be supplied from slag. During the initial stage of the reaction, $\mathrm{Al}$ was released from the slag in a highly alkaline environment and reacted mostly with the silica fume as well as fly ash, resulting in the formation of aluminosilicate gel. On the other hand, the $\mathrm{Si} / \mathrm{Al}$ ratio of the C-S-H gel, formed mostly from the slag, increased due to the participation of some of the $\mathrm{Al}$ dissolved from the slag in the formation of the aluminosilicate gel. Therefore, the $\mathrm{Si}$ and $\mathrm{Al}$ in the slag contributed to the formation of both the aluminosilicate and the C-S-H gel in the samples where fly ash or slag was replaced with silica fume, thus increasing the reactivity of the slag.

3.4. Compressive Strength. Figure 6 shows the compressive strength results of the geopolymer incorporating silica fume. Here, SF1-10 and SF1-20 with silica fume type 1 had very low compressive strength of 3.22 and $3.37 \mathrm{MPa}$, respectively, while SF2-10, SF2-20, and SF2-10S with silica fume type 2 had the corresponding compressive strength of $44.20,49.03$, and $41.32 \mathrm{MPa}$, with 2-SF20S showing a compressive strength of 23.39 MPa. As listed in Table 3, the insoluble Na content of alkali activator was the lowest in the geopolymer samples with SF1, and as listed in Table 5, the total reactivity was also the lowest.

The dissolution concentration of raw silica fume in a $\mathrm{NaOH}$ solution at the initial stage was measured to investigate the influence of different types of silica fume on the compressive strength. In Table 6, the silicon dissolution concentration of raw SF1 for $48 \mathrm{~h}$ was slightly higher than that of raw SF2, while the compressive strength of SF1 samples was much lower than those of SF2 samples. Thus, it appears that the 
TABLE 6: Element dissolution concentrations of raw silica fume in $\mathrm{NaOH}$ solution $(\mathrm{mg} / \mathrm{L})$.

\begin{tabular}{lccccc}
\hline Sample ID & Time & $\mathrm{Si}$ & $\mathrm{Al}$ & $\mathrm{Ca}$ & $\mathrm{S}$ \\
\hline \multirow{2}{*}{ Silica fume 1 } & $24 \mathrm{~h}$ & 169.4 & 2.895 & 0.183 & 6.087 \\
& $48 \mathrm{~h}$ & 185.3 & 2.779 & 0.162 & 5.535 \\
\hline \multirow{2}{*}{ Silica fume 2 } & $24 \mathrm{~h}$ & 119.9 & 2.479 & 0.521 & 2.990 \\
& $48 \mathrm{~h}$ & 136.6 & 2.413 & 0.175 & 1.329 \\
\hline
\end{tabular}

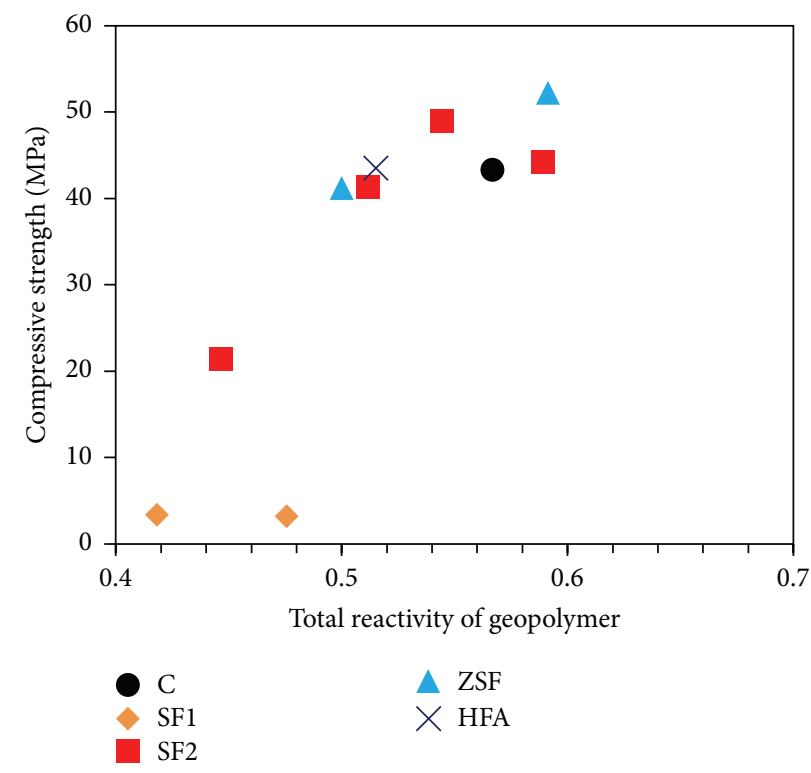

FIGURE 7: Relationship between compressive strength and total reactivity of fly ash-slag geopolymers.

difference in the Si dissolution concentration did not affect the reactivity or compressive strength of the geopolymer incorporating the silica fume. On the other hand, there was a correlation between the total reactivity and the compressive strength of the geopolymer samples in Figure 7, except in the SF1-10 and SF1-20 cases, which showed very low compressive strength. In particular, the compressive strength is closely associated with the reactivity of the slag rather than the reactivity of the fly ash.

The compressive strength of $\mathrm{C}$ was very comparable to that of HFA. The compressive strength is significantly affected by the substance replaced by silica fume. Z10, in which fly ash was substituted with silica fume, showed a compressive strength of $52.2 \mathrm{MPa}$, while Z10S, in which slag was substituted with silica fume, showed a compressive strength of 41.12 MPa. The samples in which the replacement levels of fly ash with SF2 were $10 \%$ and $20 \%$ showed an increase in the compressive strength of $1.0 \mathrm{MPa}$ and $5.8 \mathrm{MPa}$, respectively. These results are evidence of the effect of silica fume on the compressive strength. On the other hand, the samples for which the replacement of slag with SF2 was 10\% and 20\% showed a decrease in the compressive strength of $2.0 \mathrm{MPa}$ and 19.9 $\mathrm{MPa}$, respectively. In previous work, the proper amount of slag in a fly ash-slag based geopolymer was suggested as $40-50 \%$ of the total binder [26]. To obtain high mechanical properties of a geopolymer mixed with fly ash and slag, an appropriate mix ratio of the fly ash and the slag is required. In this study, the percentage of the slag in $\mathrm{C}$ was $50 \%$ and that of the slag in SF20S was 30\%, somewhat low compared to the proper content of slag (40-50\%) suggested in the literature [26]. In SF20S, where silica fume was substituted for fly ash at a rate of $20 \%$, the calcium content necessary for the formation of C-S-H was nearly constant as the slag content did not change. Thus, the compressive strength of SF20S was increased by $49.0 \mathrm{MPa}$ compared to that $(43.3 \mathrm{MPa})$ of C.

The replacement of fly ash with silica fume resulted in an increase in the compressive strength of the geopolymer. This was most likely due to the effect of silica fume acting as a microfiller in the geopolymer, with densification of the matrix resulting from the formation of the C-S-H gel due to the reaction with the slag. In particular, the compressive strength was greatly improved by $52.2 \mathrm{MPa}$ in the geopolymer incorporating zirconium silica fume. As mentioned above, the Si dissolved from the silica fume in an alkaline environment reacted with the $\mathrm{Ca}$ of the slag, resulting in the $\mathrm{C}-\mathrm{S}-\mathrm{H}$ formation. It also reacted with the $\mathrm{Al}$ of fly ash or slag, resulting in the formation of aluminosilicate. This is supported by the results shown in Table 4 and Figure 2 .

\section{Concluding Remarks}

This study presented the results and a discussion of an experimental study conducted to investigate the improved reactivity of a geopolymer based on a combination of fly ash and blast furnace slag (BFS) by the addition of silica fume. The geopolymers were synthesized by activating a mixture of fly ash, slag, and three different types of silica fume with an alkali activator. XRD and ICP-OES were utilized to investigate the reaction characteristics. The silicate structure was analyzed by ${ }^{29} \mathrm{Si} \mathrm{NMR}$ spectroscopy. The relationships between the compressive strength and the reactivity of each geopolymer sample were also evaluated. The following conclusions can be drawn from the results presented in this paper.

(1) A broad XRD peak at 29-30 assigned to C-S-H was not observed in the geopolymers incorporating SF1 but was observed in the geopolymers incorporating SF2. The geopolymers incorporating SF1 (SF1-10 and SF1-20) showed very low compressive strength at 3.22 $\mathrm{MPa}$ and $3.37 \mathrm{MPa}$, and much lower reactivity of alkali activator than the geopolymers incorporating SF2 had. The use of different types of silica fume resulted in the variation of the slag reactivity, which mostly affected the compressive strength of the fly ash/slag geopolymer.

(2) The replacement of fly ash with silica fume significantly decreased the $\mathrm{Q}^{4}(1 \mathrm{Al})$ and increased the $\mathrm{Q}^{4}(2 \mathrm{Al}), \mathrm{Q}^{4}(3 \mathrm{Al})$, and $\mathrm{Q}^{4}(4 \mathrm{Al})$. The decreased $\mathrm{Al}$ content resulting from the substitution of silica fume for fly ash was insufficient for the formation of the aluminosilicate gel in the geopolymer. Nevertheless, the $\mathrm{Si} / \mathrm{Al}$ ratio of the aluminosilicate gel was relatively constant, ranging from 2.0 to 2.6, while the $\mathrm{Si} / \mathrm{Al}$ ratio of the C-S-H gel increased with the addition of silica 
fume. Accordingly, it can be said that the additional Al necessary for the formation of aluminosilicate gel was supplied by the dissolution of the slag in the alkaline environment. Some of the $\mathrm{Al}$ dissolved from slag contributed to the formation of aluminosilicate gel, while the remnant slag particles mostly participated in the formation of the C-(A)-S-H gel with a decrease in the $\mathrm{Q}^{2}(1 \mathrm{Al})$.

(3) The reduced slag contents $(30 \%$ and $40 \%$ of the total binder) owing to the substitution of silica fume for slag make it difficult to supply sufficient Al to form the aluminosilicate gel, which disturbed the formation of $\mathrm{Q}^{4}(4 \mathrm{Al})$ in the aluminosilicate gel while also resulting in an increase in the $\mathrm{Q}^{4}(2 \mathrm{Al})$ and $\mathrm{Q}^{4}(3 \mathrm{Al})$. These results indicate that adding silica fume to the fly ashslag geopolymer changed the silicate structures of the $\mathrm{C}-\mathrm{S}-\mathrm{H}$ gel and the aluminosilicate gel.

(4) The addition of silica fume resulted in a decrease in the reactivity of the fly ash and increases in those of the slag and $\mathrm{Na}$ in the alkali activator. It appears that the alkali activator reacted more favorably with the silica fume than with the fly ash. The increase in the reactivity of slag caused by the addition of silica fume was attributed to the reaction of the $\mathrm{Al}$ in the slag with the silica fume.

(5) The improved reactivity and the more polymerized aluminosilicate structure of fly ash-slag geopolymer resulting from the addition of silica fume may provide new insight into improving durability of geopolymer, for example, chloride penetration and acid resistance.

\section{Competing Interests}

The authors declare that there is no conflict of interests regarding the publication of this paper.

\section{Acknowledgments}

This work was supported by the Power Generation \& Electricity Delivery Core Technology Program of the Korea Institute of Energy Technology Evaluation and Planning (KETEP) granted financial resource from the Ministry of Trade, Industry \& Energy, Republic of Korea (no. 20141010101860).

\section{References}

[1] http://www.geopolymer.org/news/.

[2] X. Li, X. Ma, S. Zhang, and E. Zheng, "Mechanical properties and microstructure of class $\mathrm{C}$ fly ash-based geopolymer paste and mortar," Materials, vol. 6, no. 4, pp. 1485-1495, 2013.

[3] Z. Yunsheng, S. Wei, and L. Zongjin, "Composition design and microstructural characterization of calcined kaolin-based geopolymer cement," Applied Clay Science, vol. 47, no. 3-4, pp. 271-275, 2010.

[4] J. L. Provis, G. C. Lukey, and J. S. J. van Deventer, "Do geopolymers actually contain nanocrystalline zeolites? A reexamination of existing results," Chemistry of Materials, vol. 17, no. 12, pp. 3075-3085, 2005.
[5] K. Kohno, F. Aihara, and K. Ohno, "Relative durability properties and strengths of mortars containing finely ground silica and silica fume," in Proceedings of the 3rd International Conference on Fly Ash, Silica Fume, Slag, and Natural Pozzolans in Concrete, vol. 1, pp. 815-826, Trondheim, Norway, 1989.

[6] O. Gautefall, "Effect of CSF on the diffusion of chloride through hardened cement paste," in Proceedings of the 2nd International Conference on the Use of Fly Ash, Silica Fume, Slag and Natural Pozzolans in Concrete, vol. 2, pp. 991-998, American Concrete Institute, Madrid, Spain, 1986, Publication SP-91.

[7] R. P. Khatri, V. Sirivivatnanon, and W. Gross, "Effect of different supplementary cementitious materials on mechanical properties of high performance concrete," Cement and Concrete Research, vol. 25, no. 1, pp. 209-220, 1995.

[8] A. Cheng, S.-J. Chao, and W.-T. Lin, "Effects of leaching behavior of calcium ions on compression and durability of cement-based materials with mineral admixtures," Materials, vol. 6, no. 5, pp. 1851-1872, 2013.

[9] H. M. Khater, "Effect of silica fume on the characterization of the geopolymer materials," International Journal of Advanced Structural Engineering, vol. 5, no. 1, pp. 1-10, 2013.

[10] D. Dutta, S. Thokchom, P. Ghosh, and S. Ghosh, "Effect of silica fume additions on porosity of fly ash geopolymers," Journal of Engineering and Applied Sciences, vol. 5, no. 10, pp. 74-79, 2010.

[11] F. N. Okoye, J. Durgaprasad, and N. B. Singh, "Effect of silica fume on the mechanical properties of fly ash based-geopolymer concrete," Ceramics International, vol. 42, no. 2, pp. 3000-3006, 2016.

[12] S. Thokchom, D. Dutta, and S. Ghosh, "Effect of incorporating silica fume in fly ash geopolymers," World Academy of Science, Engineering and Technology, vol. 60, pp. 243-247, 2011.

[13] P. S. Deb, P. K. Sarker, and S. Barbhuiya, "Effects of nanosilica on the strength development of geopolymer cured at room temperature," Construction and Building Materials, vol. 101, pp. 675-683, 2015.

[14] G. D. Bhavsar, K. R. Talavia, D. P. S. M. B. Amin, and A. A. Parmar, "Workability properties of geopolymer concrete using accelerator and silica fume as an admixture," International Journal for Technological Research in Engineering, vol. 1, no. 8, 2014.

[15] F. A. Memon, M. F. Nuruddin, and N. Shafiq, "Effect of silica fume on the fresh and hardened properties of fly ash-based self-compacting geopolymer concrete," International Journal of Minerals, Metallurgy and Materials, vol. 20, no. 2, pp. 205-213, 2013.

[16] A. Hajimohammadi, J. L. Provis, and J. S. J. van Deventer, “The effect of silica availability on the mechanism of geopolymerisation," Cement and Concrete Research, vol. 41, no. 3, pp. 210-216, 2011.

[17] I. Garcia-Lodeiro, A. Palomo, A. Fernández-Jiménez, and D. E. Macphee, "Compatibility studies between NASH and CASH gels. Study in the ternary diagram $\mathrm{Na}_{2} \mathrm{O}-\mathrm{CaO}-\mathrm{Al}_{2} \mathrm{O}_{3}-\mathrm{SiO}_{2}-$ $\mathrm{H}_{2} \mathrm{O}$," Cement and Concrete Research, vol. 41, no. 9, pp. 923-931, 2011.

[18] G. Engelhardt and D. Michel, High-Resolution Solid-State NMR of Silicates and Zeolites, John Wiley \& Sons, New York, NY, USA, 1987.

[19] N. K. Lee, J. G. Jang, and H. K. Lee, "Shrinkage characteristics of alkali-activated fly ash/slag paste and mortar at early ages," Cement and Concrete Composites, vol. 53, pp. 239-248, 2014.

[20] S. A. Bernal, J. L. Provis, B. Walkley et al., "Gel nanostructure in alkali-activated binders based on slag and fly ash, and effects 
of accelerated carbonation," Cement and Concrete Research, vol. 53, pp. 127-144, 2013.

[21] F. Puertas and A. Fernández-Jiménez, "Mineralogical and microstructural characterisation of alkali-activated fly ash/slag pastes," Cement and Concrete Composites, vol. 25, no. 3, pp. 287292, 2003.

[22] C. K. Yip, G. C. Lukey, and J. S. J. van Deventer, "The coexistence of geopolymeric gel and calcium silicate hydrate at the early stage of alkaline activation," Cement and Concrete Research, vol. 35, no. 9, pp. 1688-1697, 2005.

[23] I. Ismail, S. A. Bernal, J. L. Provis, R. San Nicolas, S. Hamdan, and J. S. J. van Deventer, "Modification of phase evolution in alkali-activated blast furnace slag by the incorporation of fly ash," Cement and Concrete Composites, vol. 45, pp. 125-135, 2014.

[24] N. Lee and H. Lee, "Reactivity and reaction products of alkali-activated, fly ash/slag paste," Construction and Building Materials, vol. 81, pp. 303-312, 2015.

[25] A. Buchwald, H. Hilbig, and C. Kaps, "Alkali-activated metakaolin-slag blends-performance and structure in dependence of their composition," Journal of Materials Science, vol. 42, no. 9, pp. 3024-3032, 2007.

[26] N. K. Lee and H. K. Lee, "Setting and mechanical properties of alkali-activated fly ash/slag concrete manufactured at room temperature," Construction and Building Materials, vol. 47, pp. 1201-1209, 2013. 

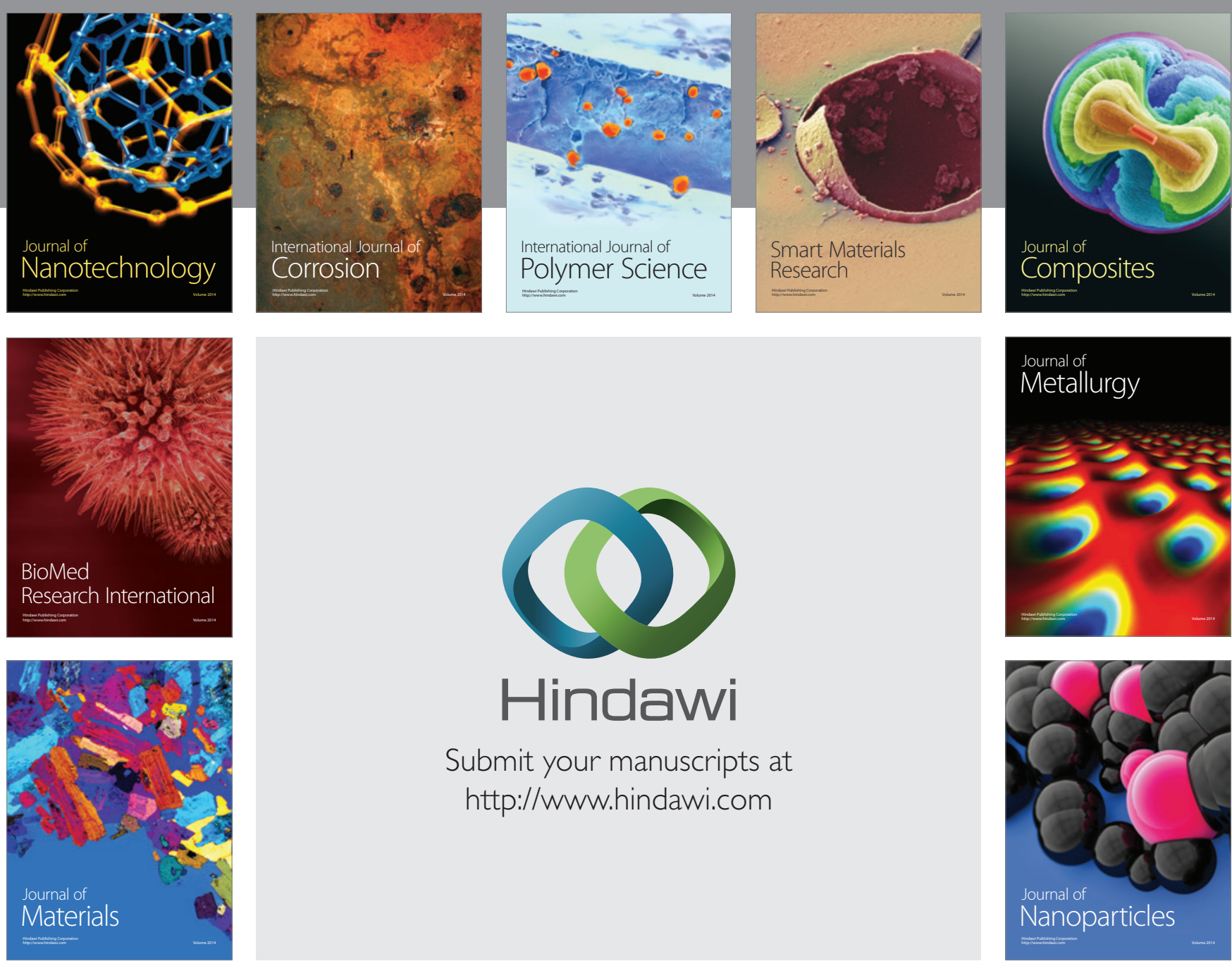

\section{Hindawi}

Submit your manuscripts at

http://www.hindawi.com

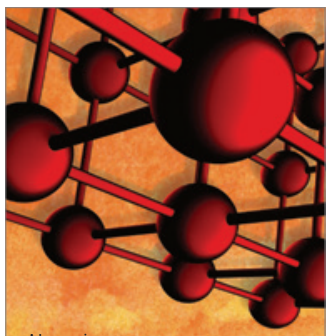

Materials Science and Engineering
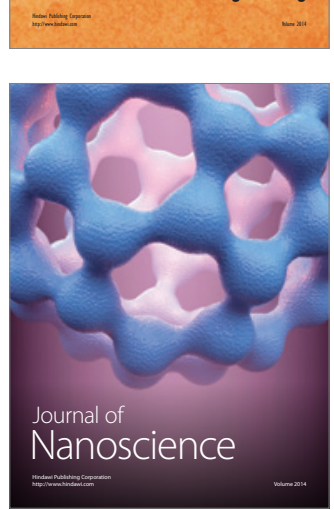
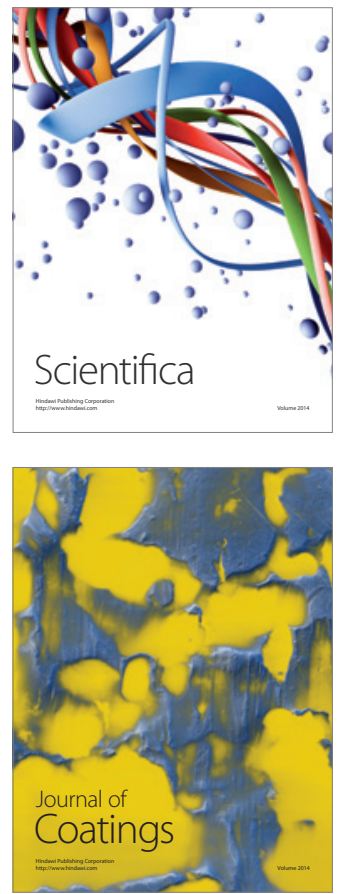
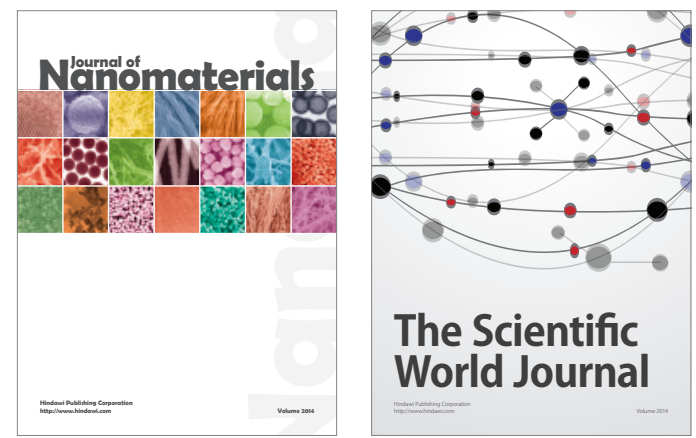

The Scientific World Journal
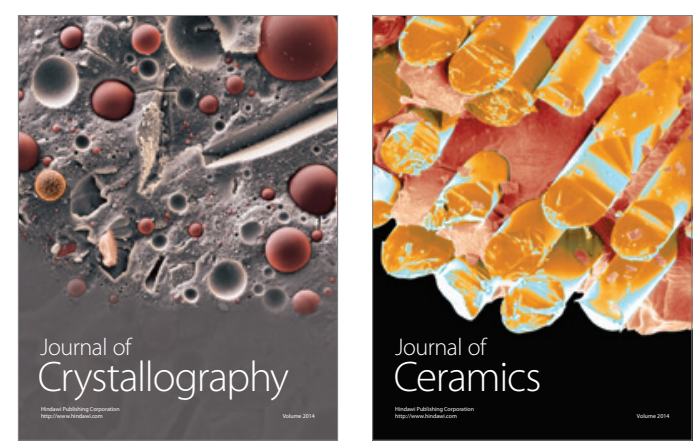
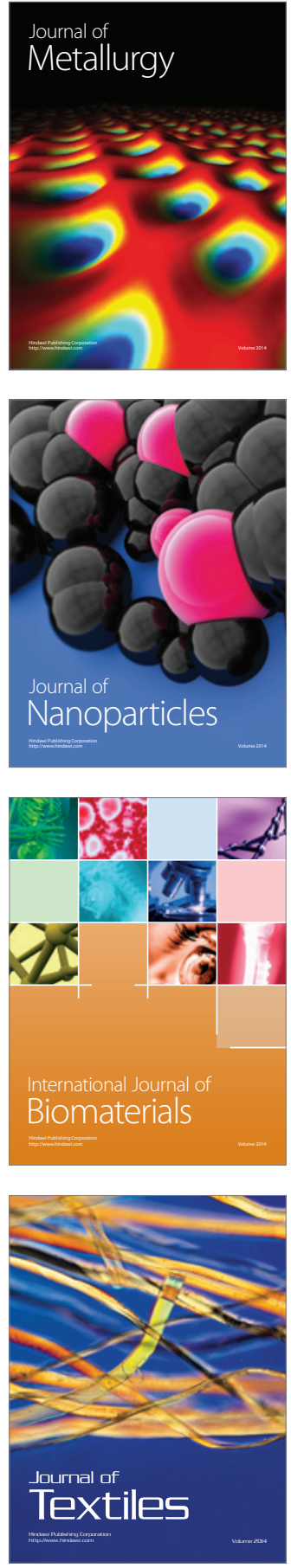